\title{
Management of Dentigerous Cyst: A Review Article
}

\author{
Nanda Rachmad Putra Gofur ${ }^{1 *}$, Aisyah Rachmadani Putri Gofur ${ }^{2}$, Soesilaningtyas ${ }^{3}$, Rizki Nur Rachman Putra Gofur ${ }^{4}$, Mega Kahdina ${ }^{4}$, \\ Hernalia Martadila Putri ${ }^{4}$, \\ ${ }^{1}$ Department of Health, Faculty of Vocational Studies, Universitas Airlangga, Surabaya, Indonesia. \\ ${ }^{2}$ Faculty of Dental Medicine, Universitas Airlangga, Surabaya, Indonesia. \\ ${ }^{3}$ Department of Dental Nursing, Poltekkes Kemenkes, Surabaya, Indonesia. \\ ${ }^{4}$ Faculty of Medicine, Universitas Airlangga, Surabaya, Indonesia.
}

*Corresponding author: Nanda Rachmad Putra Gofur, Department of Health, Faculty of Vocational Studies, Universitas Airlangga, Surabaya, Indonesia.

Received date: March 18, 2021: Accepted date: April 07, 2021: Published date: April 10, 2021

Citation: N Rachmad Putra G, A Rachmadani Putri G, Soesilaningtyas, Rizki N R P Gofur, M Kahdina, et al. (2021) Management of Dentigerous Cyst: A Review Article. Journal of Clinical Surgery and Research. 2(1) DOI: 10.31579/2768-2757/009

Copyright: (02021 Nanda Rachmad Putra Gofur, This is an open-access article distributed under the terms of the Creative Commons Attribution License, which permits unrestricted use, distribution, and reproduction in any medium, provided the original author and source are credited.

\begin{abstract}
Introduction: Dentigerous cyst is a pathological epithelial cavity that surrounds an unerupted tooth crown. Dentigerous cysts are usually associated with impacted teeth, mandibular third molars, first and second premolars and canines. Dentigerous cysts can occur at any age, but most cases of these cysts occur at the age of approximately 20 years. Men are affected more often than women. Purpose.To find out how the mechanism of dentigerous cysts. The cyst cavity is lined with epithelial cells derived from the epithelial enamel that is reduced from the tooth-forming organs. According to its pathogenesis, the pressure exerted by an erupted tooth on the follicle can block venous flow leading to accumulation of exudate between the reduced enamel epithelium and the crown of the tooth. These cysts are mostly due to fluid accumulation either between the reduced enamel epithelium and the enamel or between the layers of the enamel organ. This fluid accumulation occurs as a result of the pressure exerted by the erupting tooth on the affected follicle, which blocks venous flow, thus inducing rapid transudation of serum in the capillary walls.
\end{abstract}

Discussion: The expansion of the dentigerous cyst causes the release of bone resorbing factor and an increase in the osmolarity of the cyst fluid as a result of the discharge of inflammatory cells, the discharge of residual epithelial enamel and tooth enamel, and desquamation of epithelial cells into the lumen of the cyst. In theory, the fluid will cause cystic proliferation. because the hyperosmolar content produced by cellular breakdown and cell products causes an osmotic gradient to pump fluid into the lumen of the cyst or it can also be said that an increase in the osmolarity of cyst fluid is the result of a shortcut to inflammatory cells and desquamation of epithelial cells into the lumen of the cyst resulting in a dentigerous cyst.

Conclusion: The dentigerous cysts that surround the unerupted dental crowns are caused by the accumulation of fluid either between the reduced enamel epithelium or between the layers of the enamel organs. Dentigerous cysts can cause infection, pain, swelling, root dislocation, and resorption of adjacent tooth roots.

Keywords: dentigerous cyst, impaction, tooth

\section{Introduction}

Cyst is a pathological cavity that is filled with fluid or semi-fluid, limited by the epithelium, or not and can cause intraoral and extraoral enlargement which can clinically resemble a benign tumor (Neville et al, 2002). Cysts are classified into 3 major groups, namely cysts on the jaw, cysts associated with the maxillary antrum, and soft tissue cysts on the face, face and neck. Odontogenic cysts are the most common form of cystic lesions affecting the maxillofacial region [1].

Odontogenic cysts are the most common form of cystic lesions that appear in the maxillofacial region because of the large amount of odontogenic epithelial residue remaining in the tissue. The epithelium in the formation of cysts in the jaw originates from the remaining tissue of the dental lamina and the remaining cells from Serres (cell rests of Serres) and the shrinkage of the enamel epithelium that makes up the dentin follicles due to the growth of teeth and the remaining cells from Malassez (cell rests of Malassez) [2, 3].

Dentigerus cyst, also known as follicular cyst, is a cyst that covers part or all of a tooth crown that does not grow and is attached to the tooth root (amelocemental junction). These cysts come from shrinkage of the remaining tooth enamel which is the result of accumulation of fluid between the layer of the tooth crown and the epithelial wall of the tooth enamel that has shrunk that lines the tooth follicle. The epithelium that covers it is a stratified squamous epithelium. The goal of treatment for dentigerous cysts is to eliminate pathological abnormalities and preserve the tooth with minimal surgical intervention. The choice of treatment type 
depends on the size and location of the cyst, the patient's age, the tooth involved, the stage of root development, the position of the tooth involved in the jaw and the relationship with the adjacent tooth and the involvement of the vital structures $[4,5]$.

\section{Discussion}

\section{Prevalence and Etiology}

Dentigerous cysts are the second most common odontogenic cysts after radicular cysts. Occurs in almost every age group but the highest incidence was found in the decade of the 30 s and 40 s, occurs more often in men than women, and 5 times more common in white people than black people. The white population in South Africa has a significantly higher incidence of tooth impaction than the black population and this seems to be the reason for the higher incidence of dentigerous cysts in whites than in blacks. These cysts are twice as common in the mandible than in the maxilla, and most commonly affect impacted or late erupted teeth / are generally associated with mandibular third molars and are of lesser frequency in the canines of the jaw [7].

The cause of cysts is sometimes unknown, but usually the result of an inflammatory process, trauma, or because of an embryogenic defect. But in general, most odontogen cysts occur as a result of the proliferation of epithelial remnants at the time of tooth development. The epithelium that plays a role in the process of odontogenic cysts is as follows [8]:
1. Epithelial rests of Malassez are epithelium formed as a result of the fragmentation process of the epithelial root sheath of Hertwig during odontogenesis. This epithelium plays a role in the formation of radicular cysts, residual cysts, and paradental cysts.

2. Reduced enamel epithelium is the epithelium originating from the enamel of the organ and covering the unerupted tooth crown. This epithelium plays a role in the formation of dentigerous cysts and erupted cysts. The etiology of dentigerous cysts is usually associated with impacted teeth, delayed eruption of teeth, tooth development, and odontoma [9].

3. Glands of Serres is the epithelium that remains after dissolution of the dental lamina. This epithelium plays a role in the odontogenic growth of keratocysts, lateral cysts, and gingival cysts.

\section{Clinical Examination of Dentigerous Cyst}

Dentigerous cysts are the cysts most commonly associated with impacted third molars in the mandible, maxillary canines, maxillary third molars, and mandibular second premolars. Most found in the second and third decades of age, more in men than women, with a ratio of 1.6 to 1 . Usually asymptomatic, but there is a delay in eruption which is the most frequent indication of the formation of dentigerous cysts. These cysts have the ability to reach significant sizes, usually associated with expansion of cortical bone but rarely enlarge in patients predisposed to cause pathological fractures [10].

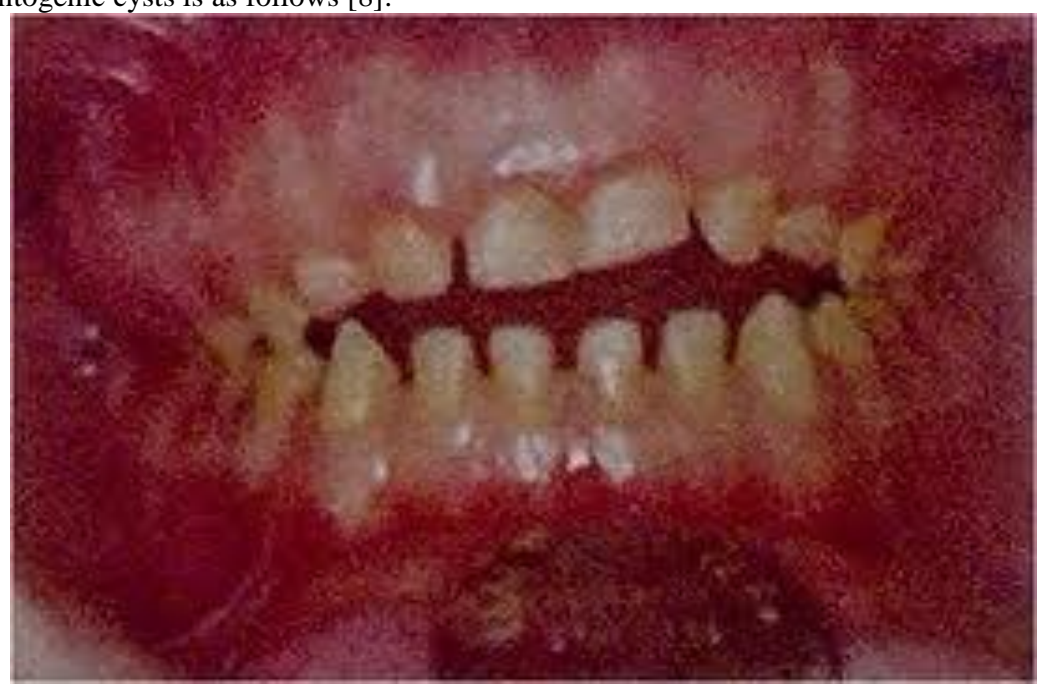

Figure 1: Clinical picture of dentigerous cyst

Clinical examination also revealed missing teeth and positive swelling and induration, facial asymmetry and possible pathological fracture. Patients usually find out after a dental x-ray. Patients reported not always feeling pain or discomfort. Approximately $4 \%$ of patients with unerupted teeth have dentigerous cystic lesions. Dentigerous cysts can also occur around supernumerary teeth in about $5 \%$ of all dentigerous cysts [8].

Radiographically, the dentigorous cyst shows a well-defined, unilocular or multilocular radiolucent with a contical margin that corresponds to the un-erupted crown of the tooth. This unerupted tooth is usually replaced. In the mandible the radiolucent connection extends superiorly from the third molar to the ramus or anterior inferiorly along the mandible. In maxillary dentigerous cysts affecting the canine region, extension occurs into the maxillary sinus or to the orbital floor. The absorption of the roots attached to the erupted teeth can also be seen [10].

On radiographs of the dentigerous cyst, a unilocular radiolucent area that is associated with the dental crown is seen. The normal size of the follicular space is less than $2.5 \mathrm{~mm}$ on intraoral radiographs and $3 \mathrm{~mm}$ on panoramic radiographs, if the visible size is larger, the formation is considered a cyst. Radiographically, the internal aspects of the cyst appear radiolucent except for the crown of the tooth involved. Cysts appear translucent and compressible. When the cyst expansion causes cortical bone resorption [11]. 


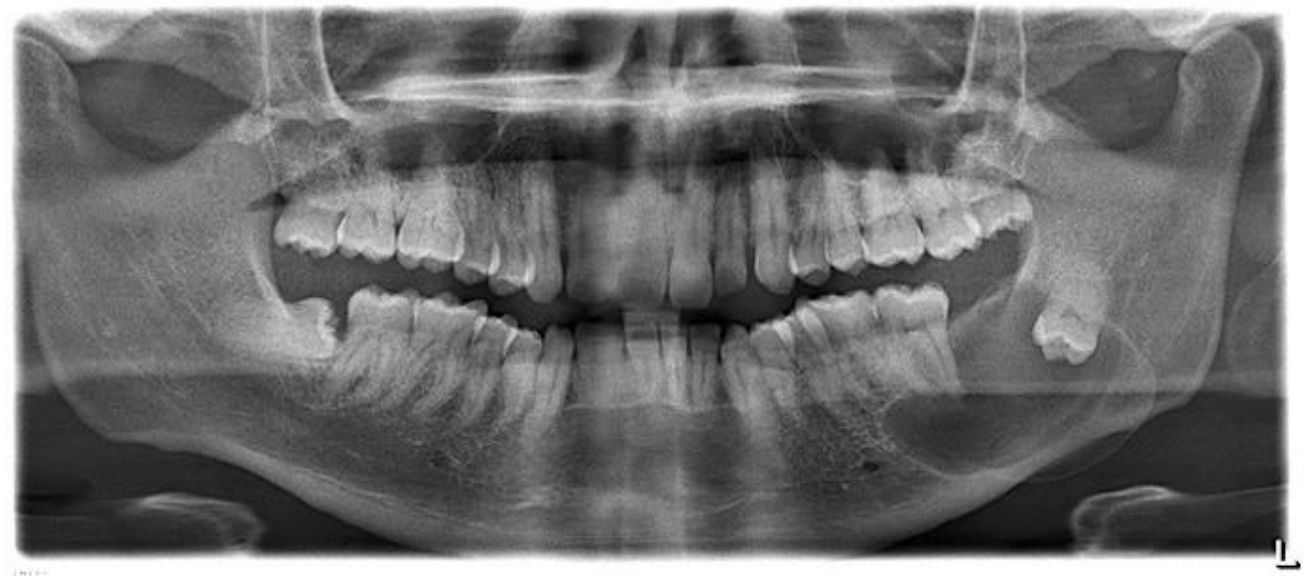

Figure 2: Dentigerous Cyst Radiology[12].

\section{Management of Dentigerous Cyst}

There are two methods used to treat cysts, namely enucleation and marsupialization. Enucleation is the complete removal of the cyst lining. Enucleation is generally used when the cyst layer is easily separated from the adhesions of the bone and the cavity contains a blood clot. Enucleation can be performed on all small to medium sized cysts [13].

A standard mucoperiosteal flap is performed in the buccal region with a vertical incision. The thinned bone is removed with bone rongeurs or burs to gain surgical access to the fluid passage. The edge of the cyst is then separated by a periosteal elevator or curette from the bony bone. The edge of the cyst should be sent to the histopathologic department. After irrigation with sterile saline, the flap was sutured back into its anatomical position. If root canal filling has been performed, the apicoectomy procedure should be performed at the same time as re-closure of the canal when the timing is right [14].

Postoperative complications are rare, although wound damage in large mandibular cysts may occur. Patients normally undergo control 4-6 months after surgery. Marsupialization is the return of the cyst to its original state. Indications include cooperative patients, if enucleation is too risky, for large radicular cysts or dentigerous cysts in children. The advantages of the marsupialization technique include less pain and bone growth followed by shrinkage of the lesion. The disadvantages, among others, take a relatively long time [15].

Marsupialization means making a pocket. This treatment technique involves completely destroying the cyst. The effect of this technique is to relieve pressure on the cyst cavity, stop continuous expansion, and promote shrinkage of the cyst's edge or layer in the presence of new bone formation in the surrounding area. This technique is recommended when enucleation feels very dangerous to vital structures such as the inferior nerve of the tooth or there is a risk of fracture during the enucleation procedure [16, 17].

Marsupialisation can easily be achieved by extracting the tooth associated with the cyst, aspirating all of the socket contents and then irrigation of the lumen of the cyst prior to opening with a surgical pack. Sterile ribbon gauze soaked in whitehead varnish is intended as an antiseptic to avoid infection of the cyst cavity. The pack is then placed in the socket as a replacement tooth with an acrylic root that is extended into the cavity of the cyst from the socket. The cyst cavity was then irrigated with warm saline twice daily $[18,19]$.

\section{Conclusion}

The prognosis of some cysts is very good, it rarely recurs after complete cyst removal. Several potential complications must be considered, particularly the possibility that the dentigerous cyst lining can transform into ameloblastoma. But the frequency of occurrence of these neoplastic transformations is low. There may be multiple intraosseous mucoepidermoid carcinomas growing from mucous cells at the border of the dentigerous cyst.

\section{References}

1. Neville, Damm DD, Allen CM, Bouquot JE. (2002) Oral and maxillofacial pathology 2 nd ed. St. Louis: Saunders. H. 611619.

2. Ko KS, Dover DG, Jordan RC. (1999) Bilateral dentigerous cysts--report of an unusual case and review of the literature. J Can DentAssoc. 65(1):49-51.

3. Ko KSC, Dover DG, Jordan RCK. (2007) Bilateral dentigerous cystc - report of an unusual case and review of the literature. Canadian Dental association, J Can Dent Assoc.

4. Freddy G. Kuhuwael, Nova Pieter, Nasrul. (2009) Kista odontogenik di Rumah Sakit Dr. Wahidin Sudirohusodo Makassar. Dentofasial, Vol.82 8, No.2, :80-87.

5. Dunlap C. (2000) Cysts of the jaws. Kansas: School of Dentistry University of Missouri. 1-8.

6. Freitas DQ, Tempest LM, Sicolis E, Lopes-Neto FC. (2006) Bilateral dentigerous cysts: review of the literature and report of anunusual case. DentomaxillofacRadiol. 35(6):464-468.

7. Ustuner E, Fitoz S, Atasoy C, Erden I, Akyar S. (2003) Bilateral maxillarydentigerous cysts: a case report. Oral Surg Oral Med OralPathol Oral RadiolEndod. 95(5):632-635.

8. Oliveira Gj, Jose N, Lois N, Lisa G. (2008) Conservative Management of A Dentigerous Cyst Secondary To Primary Tooth Trauma. Dent Traumatol. 24:676-679.

9. Shear M, Speight P. (2007) Cysts of the oral and maxillofacial region 4 th edition. 76-77.

10. Sudiono, J, Kurniadhi, B, Hendrawan, A, Djimantoro, B. (2003) Ilmu Patologi. EGC: Jakarta. Hlm.

11. Shane McCrea MSc, BDS, LDSRCS, MFGDP (UK). (2009) Adjacent dentigerous cysts with ectopic displacement of a third mandibular molar and supernumerary (forth) molar: a rare occurence.

12. Mihailova, Nikolov, Slaukov. (2008) Diagnostic imaging of dentigerous cysts of the mandible. 1-3.

13. Oliveira GJ, Jose N, Lois N, Lisa G. (2008) Conservative management of a dentigerous cyst secondary to primary tooth trauma. Dent Traumatol. 24: 676-679. 
14. Shawneen GM, Peter S, Jeffrey P, Peter G. (2011) A dentigerous cyst associated with bilaterally impacted mandibular canine in a girl: a case report. J Med Case Report.

15. Smith RA. (2004) Spesific atypes of jaw cyst in jaw cysts. In: A Lange Medical Book: Current diagnostic and treatment in otolaryngologyhead and neck surgery. Lalwani AK, editor. Boston: Mc. Grew Hill Companies. 390-403.

16. Desai RS, Vanaki SS, Puranik RS, Tegginamani AS. (2005) Dentigerous cyst associated with permanent central incisor: a rare entity.J Indian SocPedod Prev Dent. 23(1):49-50.

17. Wray D, Stenhouse D, Lee D, Clark A. (2003) Textbook of general and oral surgery. 229-232.

18. Ahmed NM, Speculand B. (2012) Removal of ectopic mandibular third molar teeth: literature review and report of three cases. Oral Surgery. 5:39-44.

19. Subhangi M, Raju R, Doshi, Imtiyaz N. (2009) Dentigerous cyst associated with impacted permanent maxillary canine. People's J Sci Res. 2(2):1-4. 